\title{
A Trial-by-Trial Window into Sensorimotor Transformations in the Human Motor Periphery
}

\author{
(1)Chao Gu, ${ }^{1,3}$-Daniel K. Wood, ${ }^{5}$-Paul L. Gribble, ${ }^{1,2,3}$ and $\oplus^{-B r i a n}$ D. Corneil ${ }^{1,2,3,4}$ \\ ${ }^{1}$ Department of Psychology and ${ }^{2}$ Department of Physiology and Pharmacology, University of Western Ontario, London, Ontario, Canada N6A 5B7, ${ }^{3}$ Brain \\ and Mind Institute and ${ }^{4}$ Robarts Research Institute, University of Western Ontario, London, Ontario, Canada N6A 5B7, and 5Department of Neurobiology, \\ Northwestern University, Evanston, Illinois 60208
}

The appearance of a novel visual stimulus generates a rapid stimulus-locked response (SLR) in the motor periphery within 100 ms of stimulus onset. Here, we recorded SLRs from an upper limb muscle while humans reached toward (pro-reach) or away (anti-reach) from a visual stimulus. The SLR on anti-reaches encoded the location of the visual stimulus rather than the movement goal. Further, SLR magnitude was attenuated when subjects reached away from rather than toward the visual stimulus. Remarkably, SLR magnitudes also correlated with reaction times on both pro-reaches and anti-reaches, but did so in opposite ways: larger SLRs preceded shorter latency pro-reaches but longer latency anti-reaches. Although converging evidence suggests that the SLR is relayed via a tectoreticulospinal pathway, our results show that task-related signals modulate visual signals feeding into this pathway. The SLR therefore provides a trial-by-trial window into how visual information is integrated with cognitive control in humans.

Key words: cognitive control; human; reaching; visual processing

\section{Significance Statement}

The presentation of a visual stimulus elicits a trial-by-trial stimulus-locked response (SLR) on the human limb within $100 \mathrm{~ms}$. Here, we show that the SLR continues to reflect stimulus location even when subjects move in the opposite direction (an antireach). Remarkably, the attenuation of SLR magnitude reflected the cognitive control required to generate a correct anti-reach, with greater degrees of attenuation preceding shorter-latency anti-reaches and no attenuation preceding error trials. Our results are strikingly similar to neurophysiological recordings in the superior colliculus of nonhuman primates generating anti-saccades, implicating the tectoreticulospinal pathway. Measuring SLR magnitude therefore provides an unprecedented trial-by-trial opportunity to assess the influence of cognitive control on the initial processing of a visual stimulus in humans.

\section{Introduction}

The reaction time (RT) for almost all visually guided movements far exceeds the minimum conduction time between sensory input and motor output, allowing time for deliberation and strategic action (Luce, 1986; Posner, 1986; Carpenter and Williams, 1995; Schall, 2003). Such behavioral flexibility is captured in tasks in which subjects are instructed to move away from rather than

Received March 17, 2016; revised June 20, 2016; accepted June 22, 2016.

Author contributions: C.G., D.K.W., and B.D.C. designed research; C.G. and P.L.G. performed research; C.G. and B.D.C. analyzed data; C.G. and B.D.C. wrote the paper.

This work was supported by the Natural Sciences and Engineering Research Council of Canada (Grant RGPIN311680 to B.D.C. and Grant RGPIN-238338 to P.L.G.) and the Canadian Institutes of Health Research (Grant MOP93796 to B.D.C.). C.G. was supported by an Ontario Graduate Scholarship and a Natural Sciences and Engineering Research Council of Canada Alexander Graham Bell Canada Graduate Doctoral Scholarship. We thank H. Yang for technical assistance, T. Doherty for advice on electrode insertion, and J. A. Pruszynski for helpful discussions.

The authors declare no competing financial interests.

Correspondence should be addressed to Dr. Brian D. Corneil, Robarts Research Institute, University of Western Ontario, 1151 Richmond St. N, London, Ontario, Canada N6A 5B7. E-mail: bcorneil@uwo.ca.

DOI:10.1523/JNEUROSCI.0899-16.2016

Copyright $\odot 2016$ the authors $\quad 0270-6474 / 16 / 368273-10 \$ 15.00 / 0$ toward a visual stimulus (Hallett, 1978; Georgopoulos et al., 1989). Successful performance in these tasks requires cognitive control to: (1) consolidate the instruction, (2) process stimulus location, and (3) transform stimulus location into the appropriate motor command. The neural substrates of this sensorimotor transformation has been particularly well studied in the oculomotor system of nonhuman primates (Munoz and Everling, 2004), showing, for example, that trial-by-trial representations of the visual stimulus are attenuated in many oculomotor regions by prior instruction to prepare for an anti-saccade that moves gaze diametrically away from the visual stimulus (Everling et al., 1999; Gottlieb and Goldberg, 1999; Everling and Munoz, 2000). Such trial-by-trial resolution has simply not been available in humans, so increases in average RT and error rate on anti-saccade trials have been traditional behavioral biomarkers used to assess cognitive control in healthy and clinical populations (Chan et al., 2005; Antoniades et al., 2013; Luna et al., 2015).

Recent studies have shown that the strong transient response sweeping throughout the brain after visual stimulus onset (Wurtz 
A

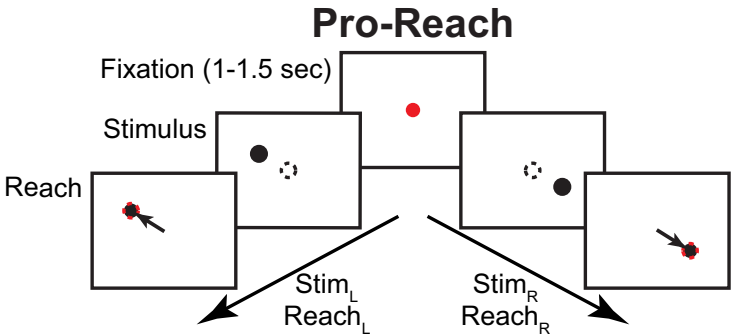

Anti-Reach
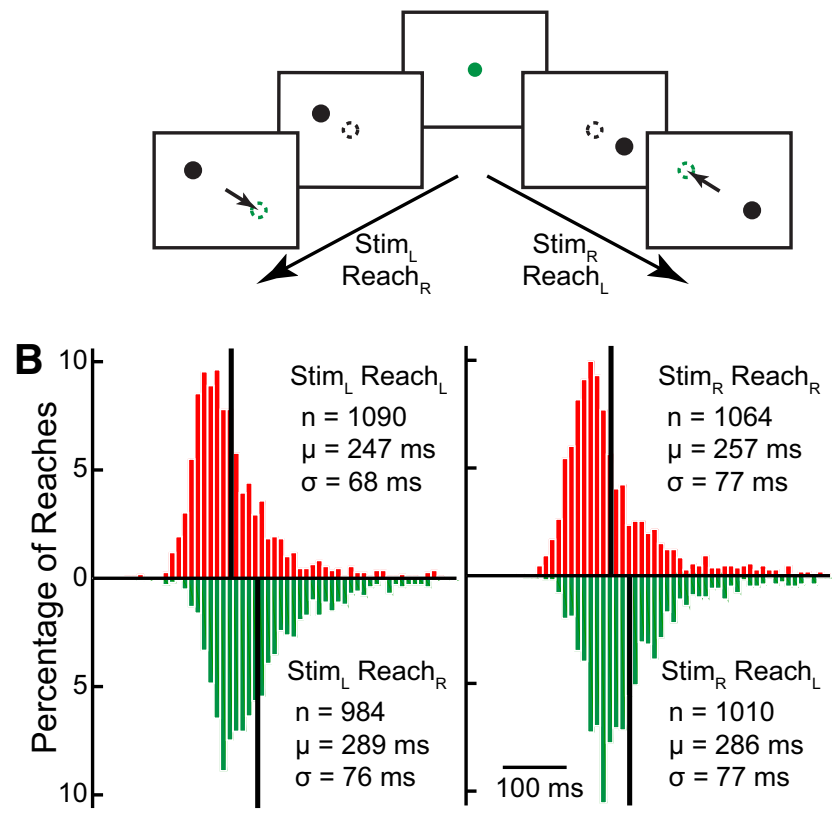

Figure 1. Pro-reach/anti-reach task and behavioral results. $A$, Timeline of the four different pro-reach/anti-reach trial conditions. The color of the central fixation circle indicated either a pro-reach (red, in this case) or anti-reach (green) trial. B, Pooled distribution of all 10 subjects' reach RT for all correct trials sorted by trial condition. Thick black line indicates the mean RT for the given RT distribution.

and Goldberg, 1972; Schmolesky et al., 1998; Churchland et al., 2010) culminates in a short-latency stimulus-locked response (SLR) on both neck (Goonetilleke et al., 2015) and upper limb muscles in humans (Pruszynski et al., 2010; Wood et al., 2015). Based on the latency of the SLR (within $100 \mathrm{~ms}$ after stimulus onset) and its temporal separation from the larger wave of muscle recruitment associated with voluntary movement, we and others have speculated that the SLR is conveyed via a reticulospinal rather than a corticospinal pathway (Pruszynski et al., 2010; Wood et al., 2015) and may therefore share the same circuitry as that generating the fast visuomotor response during corrections of ongoing reaching movements (Carlton, 1981; Goodale et al., 1986; Day and Brown, 2001). However, previous reports of the SLR had subjects reach toward a visual stimulus immediately or after an instructed delay. In doing so, these studies could not dissociate whether the SLR encoded the visual stimulus or arose as a preparatory response for the ensuing movement. Such dissociation is vital because it begins to shed light on the underlying neural substrates of the SLR.

Here, we examined the SLR on an upper limb muscle while healthy human subjects either reached toward (pro-reach) or away from (anti-reach) a peripheral visual stimulus (Fig. 1A). Our results show that the SLR encodes visual stimulus location even on anti-reach trials, so it is dissociable from the eventual movement goal. Despite being locked to the sensory input, cog- nitive control attenuated the magnitude of the SLR on individual correct, but not incorrect, anti-reach trials, with greater attenuation of the SLR preceding short-latency anti-reaches. Such trialby-trial results link directly with electrophysiological results obtained in nonhuman primates correlating the magnitude of visual responses in the oculomotor system with ensuing prosaccadic and anti-saccadic RTs (Everling et al., 1999; Everling and Munoz, 2000) and show that the SLR in humans can be used to reveal trial-by-trial fluctuations in how visual information is integrated with ongoing task demands.

\section{Materials and Methods}

Participants and procedures. A total of 10 healthy participants (nine males and one female, age 22-43, all self-declared right-handed except for one self-declared left-handed male) took part in the experiment. Subjects provided written consent, were paid for their participation, and were free to withdraw from the experiment at any time. All procedures were approved by the University Research Board for Health Science Research at the University of Western Ontario. All subjects reported no history of visual, neurological, and/or musculoskeletal disorders.

Apparatus. Parts of the apparatus, electromyography (EMG) recording setup, and data analyses have been described previously (Wood et al., 2015). Briefly, subjects performed reach movements in the horizontal plane with their right arm while grasping the handle of a robotic manipulandum (InMotion Technologies). A six-axis force transducer (ATI Industrial Automation; resolution of $0.005 \mathrm{~N}$ ) in the handle measured manual hand forces. Subjects sat at a desk and interacted with the robotic arm on a horizontal plane in line with the subject's elbow height. The $x$ and $y$-position of the manipulandum was sampled at $600 \mathrm{~Hz}$. A constant load force of $5.3 \mathrm{~N}$ ( $5 \mathrm{~N}$ to the right and $1.75 \mathrm{~N}$ toward the subject) was applied to increase the baseline activity of the limb muscle of interest. All stimuli were presented on a horizontal mirror placed just below chin level, which reflected the display of a downward-facing LCD monitor with a refresh rate of $75 \mathrm{~Hz}$. The precise timing of visual events on the LCD screen was determined by a photodiode. The subject's arm was occluded by the mirror, with real-time feedback of hand position provided by a small red cursor.

Pro-reach/anti-reach task. To initiate the task, subjects moved the cursor into a gray start circle. Once the cursor entered the circle, the color was then changed to either red or green (Fig. 1A). For five of our subjects, a red circle indicated pro-reaches and a green circle indicated anti-reaches; this was reversed for the other five subjects. After a variable delay of $1-1.5 \mathrm{~s}$, a black peripheral circle appeared $10 \mathrm{~cm}$ from the start circle at a counterclockwise rotation angle (from straight right) of either $160^{\circ}$ (a leftward stimulus) or $340^{\circ}$ (a rightward stimulus). These two locations have been reported previously to generate the SLR on the limb muscle of interest (Wood et al., 2015). The start circle was extinguished simultaneously with the presentation of the peripheral stimulus. Subjects then had to move the cursor as quickly as possible either toward (pro-reach) or $180^{\circ}$ away from (anti-reach) the peripheral stimulus. The next trial started after a short randomized delay $(0.5-1 \mathrm{~s})$. Nine of our 10 subjects performed four sessions and one subject performed three sessions of interleaved pro-reach and anti-reach trials, with each session consisting of 30 trials at each location and trial type.

Muscle recordings. Intramuscular EMG activity was recorded using fine-wire electrodes (A-M Systems) inserted into the clavicular head of the right pectoralis major (PEC) muscle (for insertion procedure, see Wood et al., 2015). Briefly, for each recording, we inserted two monopolar electrodes, enabling recording of multiple motor units. Insertions were aimed $\sim 1 \mathrm{~cm}$ inferior to the inflection point of the clavicle. All intramuscular EMG data were recorded with a Myopac Junior system (Run Technologies; low-pass filter modified to $2 \mathrm{kHz}$ ). Surface EMG was also recorded using silver-chloride electrodes and a P15 amplifier (Grass Instruments); the electrodes were placed just lateral to the intramuscular electrodes on the same muscle fiber belly. Both the surface and intramuscular EMG signals were digitized at $4 \mathrm{kHz}$.

Data analysis. To achieve sample-to-sample locking between kinematic and EMG data, kinematic data were up-sampled from 600 to 1000 

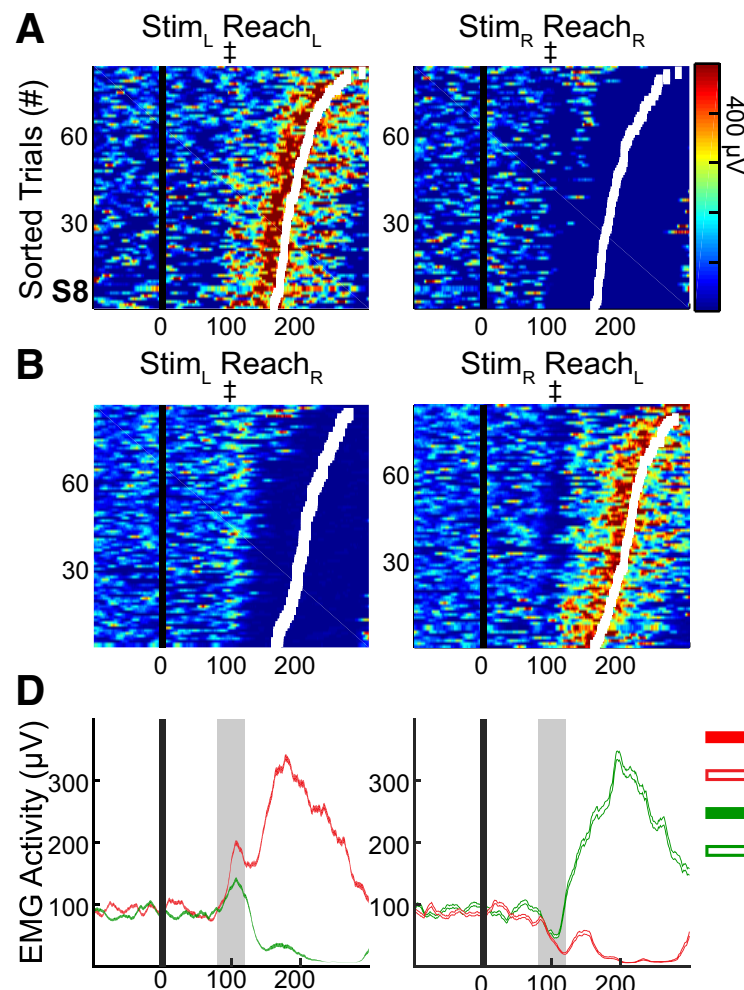

0100200

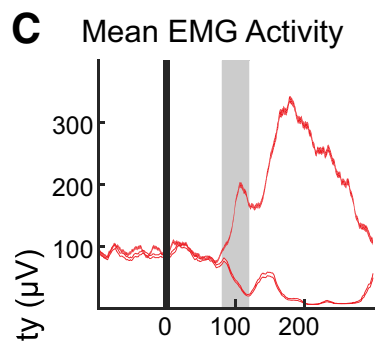

E ROC Analysis
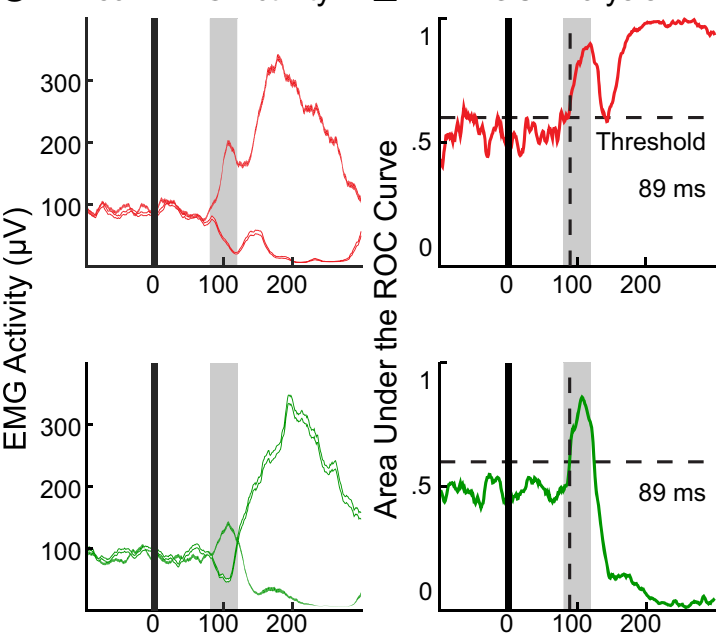

Time Aligned to Stimulus Onset (ms)

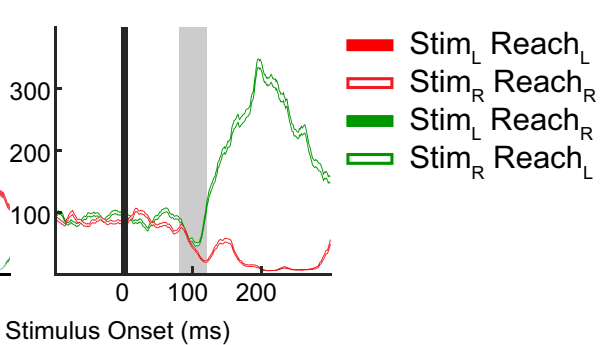

Figure 2. Intramuscular EMG results from an exemplar subject. $A$, EMG activity for correct pro-reach trials separated based on stimulus location. Each row represents activity within a single trial, with all trials aligned to stimulus onset (black line) and sorted based on reach RT (white squares). Crosses (ł) indicate the SLR epoch. $\boldsymbol{B}$, EMG activity for correct anti-reach trials (same layout as $\boldsymbol{A}$ ). C, Average EMG activity (mean \pm SEM) for leftward (Stim ${ }_{L}$, solid) and rightward $\left(S_{\text {Sim }}, 0\right.$ open) stimulus locations sorted by pro-reach or anti-reach type. D, Same layout as C except for pro-reach and anti-reach trials sorted by stimulus location. The SLR epoch (shaded box, $80-120 \mathrm{~ms}$ after stimulus onset) was significantly attenuated for anti-reach versus pro-reach trials. $\boldsymbol{E}$, Time-series ROC analyses. For each time sample (1 ms bin), the ROC value quantifies the discrimination between EMG activity for leftward and rightward stimulus locations. The discrimination time (dashed vertical line) is the first time sample in which there is a reliable separation between the EMG activities for leftward and rightward stimulus locations (see Materials and Methods).

$\mathrm{Hz}$ with a low-pass interpolation algorithm and then low-pass filtered with a second-order Butterworth filter with a cutoff at $150 \mathrm{~Hz}$. Both the intramuscular and surface recordings were rectified offline and bin integrated down to match the $1 \mathrm{kHz}$ sample rate. Reach RT was calculated as the time from the appearance of the visual stimulus (measured by a photodiode) to the initiation of the reach. Reach initiation was identified by first finding the peak tangential hand velocity and then moving backwards to the closest previous point at which the velocity profile reached $8 \%$ of the peak. Trials with RTs $<170 \mathrm{~ms}(<2 \%)$ were excluded to prevent contamination of the SLR window by voluntary recruitment associated with very-short-latency responses (Wood et al., 2015). Identification of erroneous reach trials was done on a single-trial basis using kinematic criteria in which the initial movement went $>5 \%(5 \mathrm{~mm})$ toward the incorrect direction.

Receiver-operating characteristic (ROC) analysis. Based on previous works identifying the SLR (Corneil et al., 2004; Pruszynski et al., 2010), we also used ROC analysis to detect quantitatively the presence of an SLR. We first separated the EMG activity for all correct reaches based on visual stimulus location and performed separate ROC analyses for pro-reach and anti-reach trials. For every time sample (1 ms bins) between $100 \mathrm{~ms}$ before and $300 \mathrm{~ms}$ after the visual stimulus onset, we calculated the area under the ROC curve. This metric indicates the probability that an ideal observer could discriminate the side of the stimulus location based solely on EMG activity. A value of 0.5 indicates chance discrimination, whereas a value of 1 or 0 indicates perfectly correct or incorrect discrimination, respectively. We set the thresholds for discrimination at 0.6 and 0.4 ; these criteria exceed the $95 \%$ confidence intervals of data randomly shuffled with a bootstrap procedure. The time of earliest discrimination was defined as the time after stimulus onset at which the ROC was $>0.6$ and remained above that threshold for at least 8 of the next 10 samples. Based on the ROC analysis, we defined the SLR epoch as an interval spanning $80-120 \mathrm{~ms}$ after visual onset.

\section{Results}

Across all of our subjects performing the pro-reach/anti-reach task, we found the expected increase in reach RT for anti-reach versus pro-reach trials (repeated-measures two-way ANOVA, $F_{(1,36)}=4.89, p=0.03$; Fig. $1 B$ ), but no main effect of stimulus location $\left(F_{(1,36)}=0.05, p=0.82\right)$ or interaction between stimulus location and trial type $\left(F_{(1,36)}=0.15, p=0.70\right)$. An SLR was detectable in seven of our 10 subjects during pro-reach trials $(\mathrm{SLR}+)$ using intramuscular PEC EMG recordings (see below). In five of our seven subjects, we had two separate intramuscular recordings and, in all five cases, we were able to detect an SLR on both recordings. An exemplar example of the SLR is shown in Figure 2, $A$ and $C$, illustrating an increase or a decrease in PEC EMG activity 80-120 ms (crosses and shaded box) after the presentation of leftward $\left(\right.$ Stim $_{L}$, solid) or rightward (Stim ${ }_{R}$, open) visual stimuli, respectively. The prevalence of the SLR across our sample (70\%) and the recruitment profiles were similar to that reported previously and, as before, the prevalence of the SLR did not relate simply to idiosyncratic RTs (Wood et al., 2015). Six of the 10 subjects also participated in our previous study (Wood et al., 2015). We saw consistent intrasubject reliability: three subjects were SLR+ in both studies, whereas three other subjects were SLR - in both studies. These three SLR - subjects also did not exhibit a SLR on anti-trials. Therefore, all subsequent EMG 


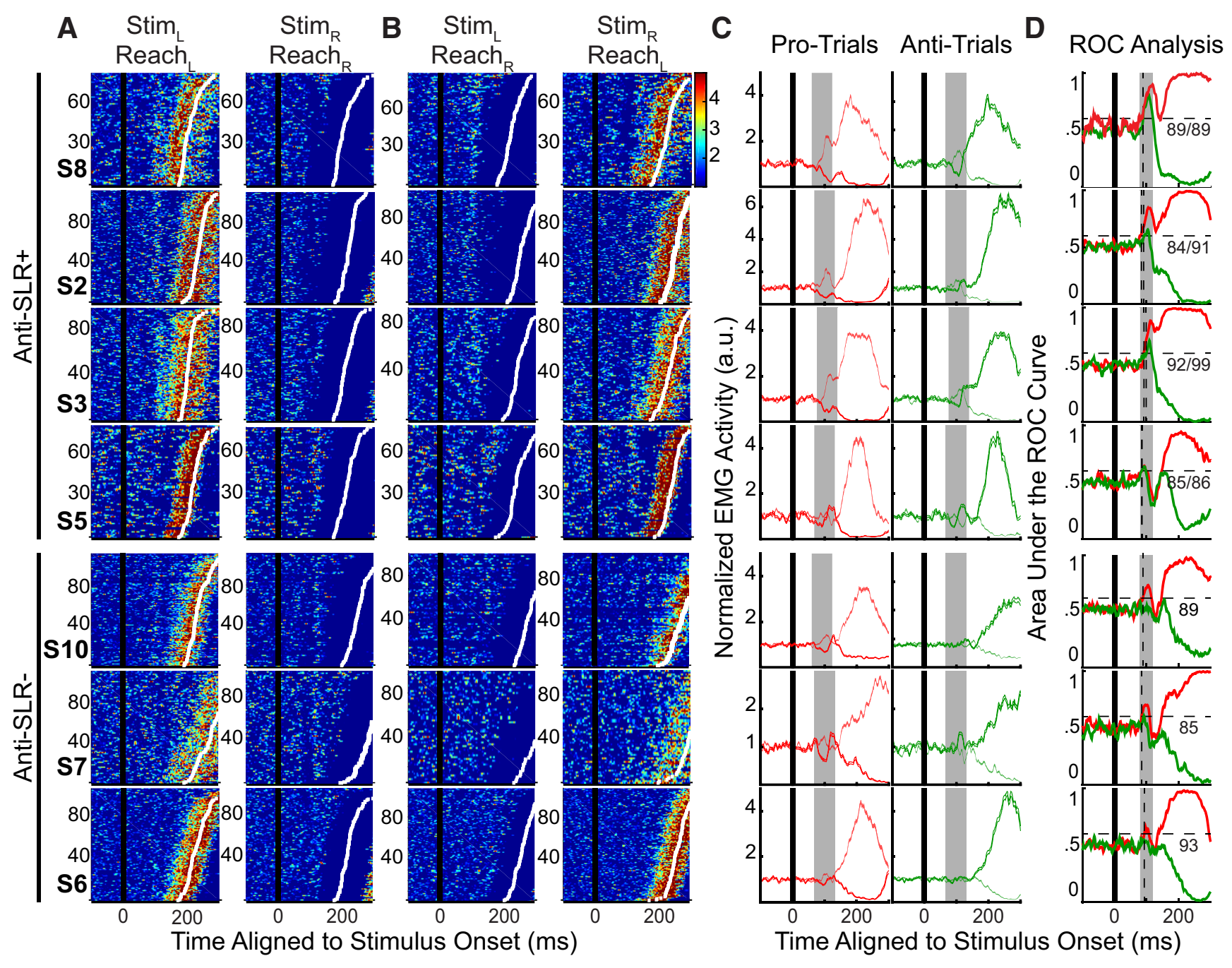

Figure 3. EMG activity from seven subjects with a detectable SLR. $\boldsymbol{A}-\boldsymbol{D}$, Same format as Figure 2 except that all EMG activity was normalized to each subject's individual baseline activity (mean EMG activity in the $100 \mathrm{~ms}$ preceding stimulus onset). The top subject is the exemplar subject from Figure 2. The top four subjects had a detectable SLR for anti-reach trials (anti-SLR + ); the bottom three subjects did not (anti-SLR-).

analyses were performed only on those seven subjects exhibiting the SLR on pro-reach trials.

SLR encodes visual stimulus rather than goal location, but is attenuated before correct anti-reaches

Figure $2 B$ also shows intramuscular PEC EMG activity from our exemplar subject during individual correctly performed antireach trials. Note how the visual stimulus on anti-reach trials continued to evoke a SLR (Fig. 2C, bottom, shaded box). Importantly, as on pro-reach trials, leftward visual stimuli (solid) evoked an increase, whereas rightward visual stimuli (open) evoked a decrease in EMG activity. The SLR recruitment profiles were the same regardless of whether the subject reached toward or away from the stimulus and thus reflected stimulus rather than goal location (Fig. 2D). This interpretation is also clearly supported by the time-series ROC analyses, in which we separated EMG activity based on stimulus location (Fig. 2E). For both proreach and anti-reach trials, note how the time-series ROC curves deflected sharply upward $>0.6$, yielding discrimination times (i.e., the first time point when there was reliable separation of EMG activity after presentation of leftward or rightward stimuli) of $\sim 90 \mathrm{~ms}$ after stimulus onset. After $\sim 120 \mathrm{~ms}$ after stimulus onset, EMG activity evolved to drive the voluntary motor com- mand, with the time-series ROC curves for both trial types returning toward chance levels $(\mathrm{ROC}=0.5)$ before diverging to 1 or 0 for pro-reach or anti-reach trials, respectively. This timeseries ROC analysis confirms that the earliest wave of EMG activity reflected the stimulus location and not the eventual reach goal direction.

All seven of our SLR + subjects exhibited discrimination times within $100 \mathrm{~ms}$ after stimulus onset for pro-reach trials (range: 84-93 ms; Fig. 3D). Four of these subjects also had similar discrimination times for anti-reaches (anti-SLR+, range: 85-99 ms top four subjects in Fig. 3). The ROC time series for the remaining three subjects failed to exceed threshold on anti-reaches, although there were hints of the SLR before anti-reach trials for subjects S7 and S10 (anti-SLR-, bottom three subjects in Fig. 3). Further, for all seven subjects, we observed that the time-series ROC analyses for both proreach and anti-reach trials were in phase $80-120 \mathrm{~ms}$ after stimulus onset, initially increasing toward threshold and then briefly decreasing at $<0.5$. As described previously (Wood et al., 2015), in subjects with longer-reach RTs, we also observed a $12-15 \mathrm{~Hz}$ oscillation of EMG activity after the SLR. This can be observed clearly in S2, S3, and S5; note the reversal of mean EMG activity before the movement-related activity (Fig. $3 C$ ) 
and how the time-series ROC analyses dip down after initially exceeding threshold (Fig. 3D).

Even though the SLR reflected visual stimulus location and occurred before the larger and later profile of PEC recruitment related to the goal location (Fig. 3, RTs denoted by white squares), it was reliably attenuated for anti-reaches compared with pro-reaches (cf. shaded boxes of Fig. $3 C$ ). As a group, for the seven subjects with an SLR, we observed an interaction between visual stimulus location and trial type during the SLR epoch, (repeated-measures two-way ANOVA, $F_{(1,24)}=10.19, p<0.01$ ). The overall difference between leftward and rightward SLR magnitude for pro-reaches was reliably greater than anti-reaches (paired $t$ test, $t_{(6)}=3.83, p<0.001$ ). When we examined the SLR response within each subject, all 7 subjects exhibited significantly greater EMG activity for pro-reach versus correct anti-reach trials (independent $t$ test, all $p<0.025$, Bonferroni corrected) after leftward visual stimulus and 6 of 7 subjects exhibited significantly weaker EMG activity (independent $t$ test, $p<0.025$, Bonferroni corrected) after rightward visual stimulus. Importantly, such differences in SLR magnitude were not simply related to differences in preparatory EMG activity for pro-reach versus anti-reach trial types because there were no differences in a baseline interval in the $40 \mathrm{~ms}$ preceding stimulus onset (repeated-measures two-way ANOVA, $F_{(1,24)}=0.62, p=0.44$, paired $t$ test, $t_{(6)}=1.01$, $p=0.35)$.

SLR generates a transient force toward the visual stimulus for both pro-reaches and anti-reaches

Previous studies of fast visuomotor responses generated during online corrective movements have quantified force profiles (Saijo et al., 2005; Franklin and Wolpert, 2008; Gallivan et al., 2016). To better compare our SLR results with these previous studies, we also examined whether the SLR on the PEC muscle was associated with a transient force toward the visual stimulus on both pro-reach and anti-reach trials. To analyze this, we separated our 10 subjects into those exhibiting the SLR on pro-reaches (SLR+; 7 subjects) or not (SLR -; 3 subjects) and determined the mean force profile for each subject individually across the four different conditions, segregated by task (pro-reach vs anti-reach) and stimulus direction (leftward vs rightward). We found that only SLR + subjects exhibited a profile in which forces diverged 110-150 ms after stimulus onset for leftward versus rightward stimuli (Fig. 4A). The timing of this divergence is consistent with the SLR epoch if we accounted for a $30 \mathrm{~ms}$ electromechanical delay (Norman and Komi, 1979). Further, consistent with EMG activity during the SLR epoch, there was a reliable interaction between stimulus direction and trial type for the mean force 110-150 ms after stimulus onset (repeated-measures two-way ANOVA, $\left.F_{(1,24)}=26.18, p<10^{-4}\right)$, with pro-reaches exhibiting a greater force difference for leftward versus rightward stimuli compared with anti-reaches (paired $t$ test, $t_{(6)}=8.55$, $p<0.001)$. In contrast, the force profiles of SLR - subjects did not diverge in the 110-150 ms interval in either the pro-reach or anti-reach trials (Fig. $4 B$, repeated-measures two-way ANOVA, $F_{(1,8)}=1.52, p=0.25$, paired $t$ test, $t_{(2)}=-1.02, p=$ $0.41)$. Therefore, the force profiles can be used as a crude proxy for the SLR on a group-level basis.

Trials with a larger SLR were associated with shorter-RT pro-reaches, but longer-RT anti-reaches

Next, we determined whether the magnitude of the SLR related in some way to the ensuing reach behavior. We first

\section{A SLR+ Subjects}

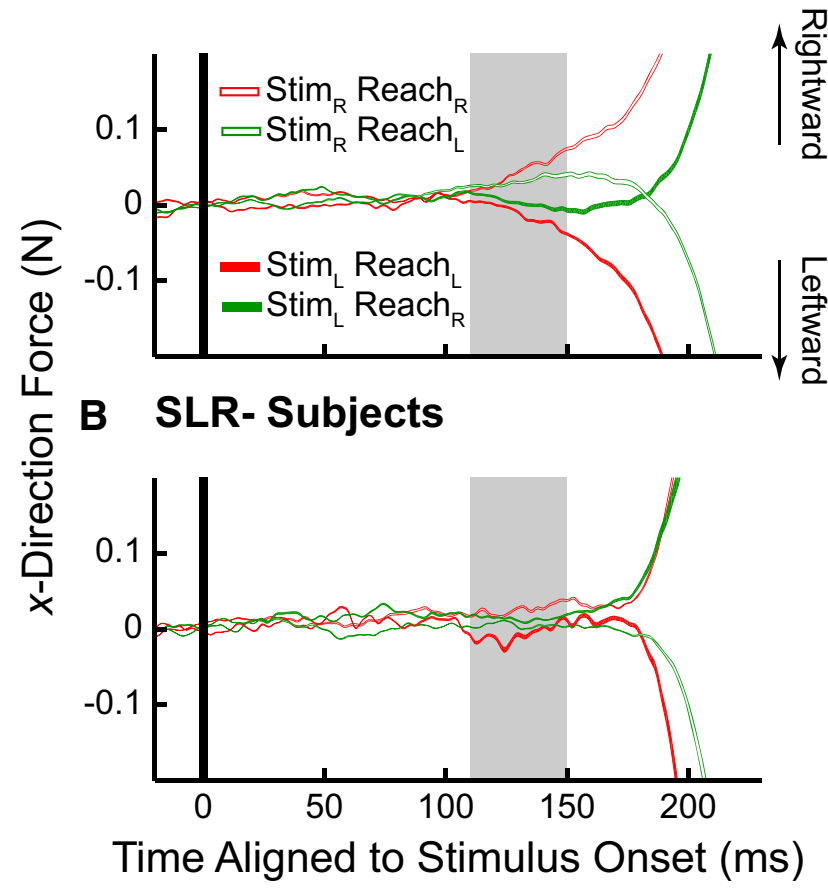

Figure 4. Kinetic force profiles offer a crude proxy for EMG activity. $A$, Mean \pm SEM $x$-direction force profiles across the four different trial conditions for the seven subjects with an SLR on pro-reach trials. An interaction was observed between the stimulus direction and trial type at 110-150 ms interval after stimulus onset (shaded box, shifted $30 \mathrm{~ms}$ after the SLR epoch). $\boldsymbol{B}$, Same format as $\boldsymbol{A}$, but for the three subjects without an SLR on pro-reach trials.

investigated the correlation between the magnitude of the SLR and the ensuing RT on a single-trial basis, doing so separately for pro-reach and anti-reach trials. Figure 5, $A$ and $B$, shows data from the subject in Figure 2, plotting reach RT against the mean EMG activity during the SLR epoch. As reported previously (Pruszynski et al., 2010) for what were by our definition pro-reaches (i.e., visually guided reaches), we observed a negative $(r=-0.31, p<0.05)$ or positive $(r=0.30, p<0.01)$ correlation for leftward or rightward stimuli, respectively (Fig. $5 A$; recall that EMG activity during the SLR epoch decreased after rightward stimuli, hence the positive correlation). In other words, larger magnitude SLRs preceded shorter RTs for pro-reaches. Remarkably, such relationships reversed on correct anti-reach trials, with positive $(r=0.23, p<0.05)$ or negative $(r=-0.31, p<0.01)$ correlations emerging for leftward or rightward stimuli, respectively (Fig. $5 B$ ). Therefore, larger-magnitude SLRs preceded longer RTs for correct antireach trials. The reversed correlations between SLR magnitude and RT can also be seen in the individual EMG traces in Figure 2, $A$ and $B$; note how EMG recruitment in the SLR epoch becomes more pronounced going from the longest (top) to shortest (bottom) RTs for leftward pro-reaches, but diminished when going from the longest to shortest RTs for rightward anti-reaches (when the subject moved away from the leftward stimulus).

We observed such correlation reversals in SLR magnitude and RTs for pro-reaches versus anti-reaches across our seven SLR+ subjects (Fig. $5 C$ ). We performed nonparametric bootstrapping analyses to determine the reliability and the reversal of these values. If there was no underlying structure to the correlation coefficients across the four different trial types, we would expect our 

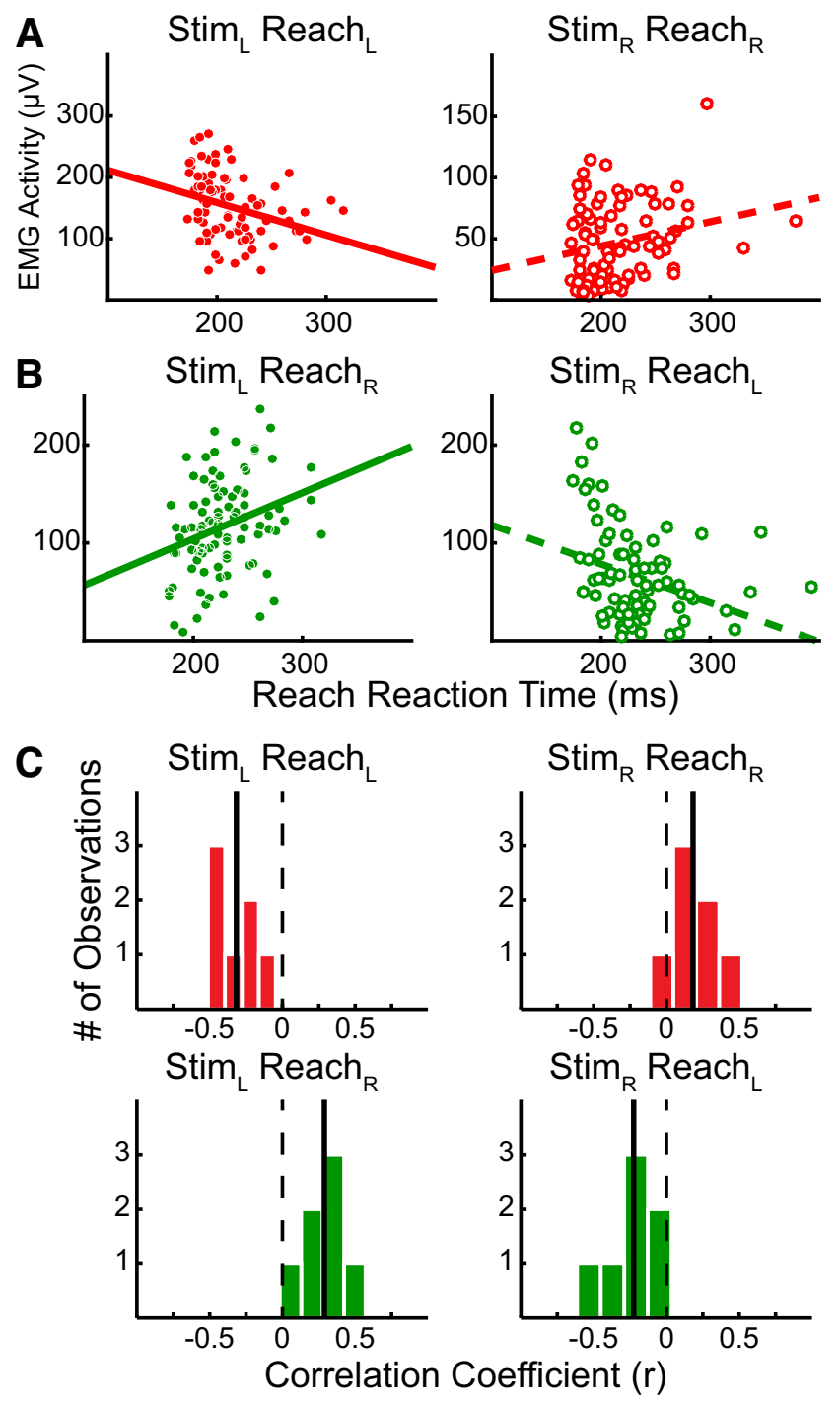

Figure 5. Reversed correlations between SLR and ensuing RT for pro-reach and anti-reach trials. Single-subject scatter plots of correlation between SLR magnitude and RT for pro-reach $(\boldsymbol{A})$ and anti-reach $(\boldsymbol{B})$ trials using data from the exemplar subject in Figure 2 are shown. $\boldsymbol{C}$, Group correlation coefficients for all seven subjects with a SLR on pro-trials even if an SLR was not detected on anti-trials. The black lines indicate the mean correlation coefficient for the four different conditions and the dashed lines indicate 0 .

observed mean correlation coefficients to fall within the distribution constructed by randomly assigned trial types (10,000 times). Instead, we found that all 4 observed means were reliably different from the bootstrapped distributions (all $p<0.05$ ). In addition, the observed differences in correlation coefficients between leftward and rightward stimuli for both pro-reach and anti-reach trials were also reliably greater than the differences obtained from the bootstrapped distributions $(p=0.0005$ and $p=0.0011$ for pro-reach and anti-reach trials, respectively). This relationship between SLR and ensuing RT was once again not simply a consequence of baseline EMG activity before stimulus onset because we did not find any reliable correlation between mean EMG activity $40 \mathrm{~ms}$ preceding stimulus onset with ensuing reach RT for any of the 4 conditions (all $p>0.09$, comparing observed correlations to a bootstrapped distribution) or any reliable difference in correlation coefficient between leftward and rightward stimuli ( $p=0.15$ and $p=0.20$, for pro-reach and anti-reach trials, respectively). These results suggest that the influence of cognitive control on the SLR is such that it reflects stimulus priority, with larger SLRs being beneficial for pro-reaches, but detrimental for anti-reaches; this pattern is similar to what has been observed in the oculomotor system (Kristjánsson et al., 2001).

\section{Similar SLR magnitudes accompanied erroneous anti-reach trials and correct pro-reach trials}

Up to now, we have only considered the SLRs for correctly performed anti-reach trials. If the SLR is truly an indicator of cognitive control, then we should expect that the SLR is also informative when subjects erroneously reach toward, rather than away from, the visual stimulus on anti-reach trials. Two of the seven SLR + subjects generated a sufficient number of erroneous anti-reach trials to permit the following analyses ( $\sim 20 \%$ error rate for both subjects, producing $>20$ erroneous trials per direction). For these two subjects, we compared SLR magnitudes across three different trial types: correct proreach, correct anti-reach, and erroneous anti-reach trials (Fig. $6)$. For both subjects, we found reliable differences between the three conditions for both leftward and rightward stimuli (repeated-measures one-way ANOVA, all $p<10^{-7}$ ). For the leftward visual stimulus, the SLR magnitude was significantly greater on erroneous (black) than correct (green) anti-reach trials (independent $t$ test, $p<10^{-7}$ and $p<10^{-5}$, Bonferroni corrected, for S3 and S8, respectively), but not significantly different between the SLRs on erroneous anti-reach and correct pro-reach (red) trials (independent $t$ test, $p=0.09$ and $p=0.88$, respectively). Similarly for rightward visual stimulus, significantly stronger SLRs were observed for erroneous versus correct anti-reach trials (independent $t$ test, $p<0.01$ and $p<0.01$, respectively; recall that the SLR is a decrease in EMG in this direction, so stronger SLRs produce greater decreases in EMG activity), but similar magnitude SLRs were observed on correct pro-reaches and erroneous anti-reaches (independent $t$ test, $p=0.30$ and $p=0.11$, respectively). Therefore, as observed for visual responses in previous neurophysiological studies during the pro-saccade/anti-saccade task (Everling et al., 1998; Everling and Munoz, 2000), the SLR on erroneous anti-reaches resembled that before correct proreaches. These results further support the idea that the SLR can be used as an indicator of cognitive control on a trial-bytrial basis.

\section{Surface EMG recordings can also detect the SLR}

To date, almost all of the previous studies on the SLR in humans or nonhuman primates have relied on intramuscular EMG recordings (Corneil et al., 2004; Chapman and Corneil, 2011; Goonetilleke et al., 2015; Wood et al., 2015). Reliance on intramuscular recordings may hinder widespread examination of the SLR in variety of paradigms in both healthy and patient populations. One study that detected SLRs with intramuscular recordings (Pruszynski et al., 2010) reported that surface EMG recordings were "almost universally unsuccessful," with only four detectable SLRs of 108 recordings. They suggested that intramuscular electrodes may be recording from slower (but first-recruited) motor units located deeper in the muscle. In sharp contrast, we were able to detect the SLR (using the same criteria as described in Materials and Methods) with surface EMG recordings in six of the seven SLR+ subjects. Figure 7 shows surface recordings from our exemplar subject, which are directly comparable to the intramuscular recordings shown in Figure 2. Although surface recordings were noisier, such recordings still exhibited all of the same 

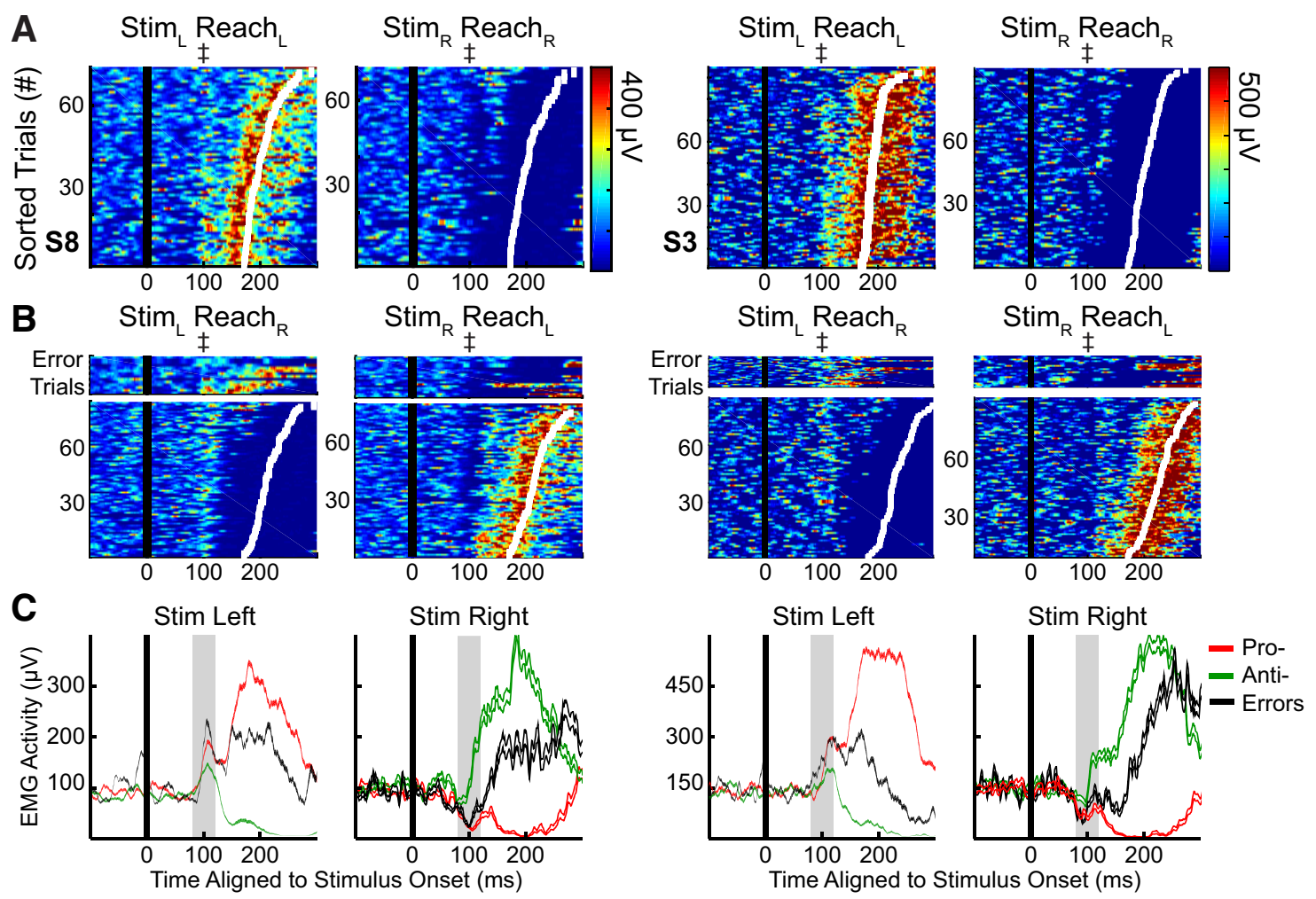

Figure 6. SLR magnitudes were similar on pro-reach and erroneous anti-reach trials. $\boldsymbol{A}-\boldsymbol{C}$, Data from the two subjects, $\mathrm{S} 3$ and $\mathrm{S} 8$, with enough erroneous anti-reach trials. Same format as in Figure 2 is shown, except erroneous anti-reach trials are displayed on top of correct anti-reach trials or shown in black. See Materials and Methods for how erroneous trials were detected.
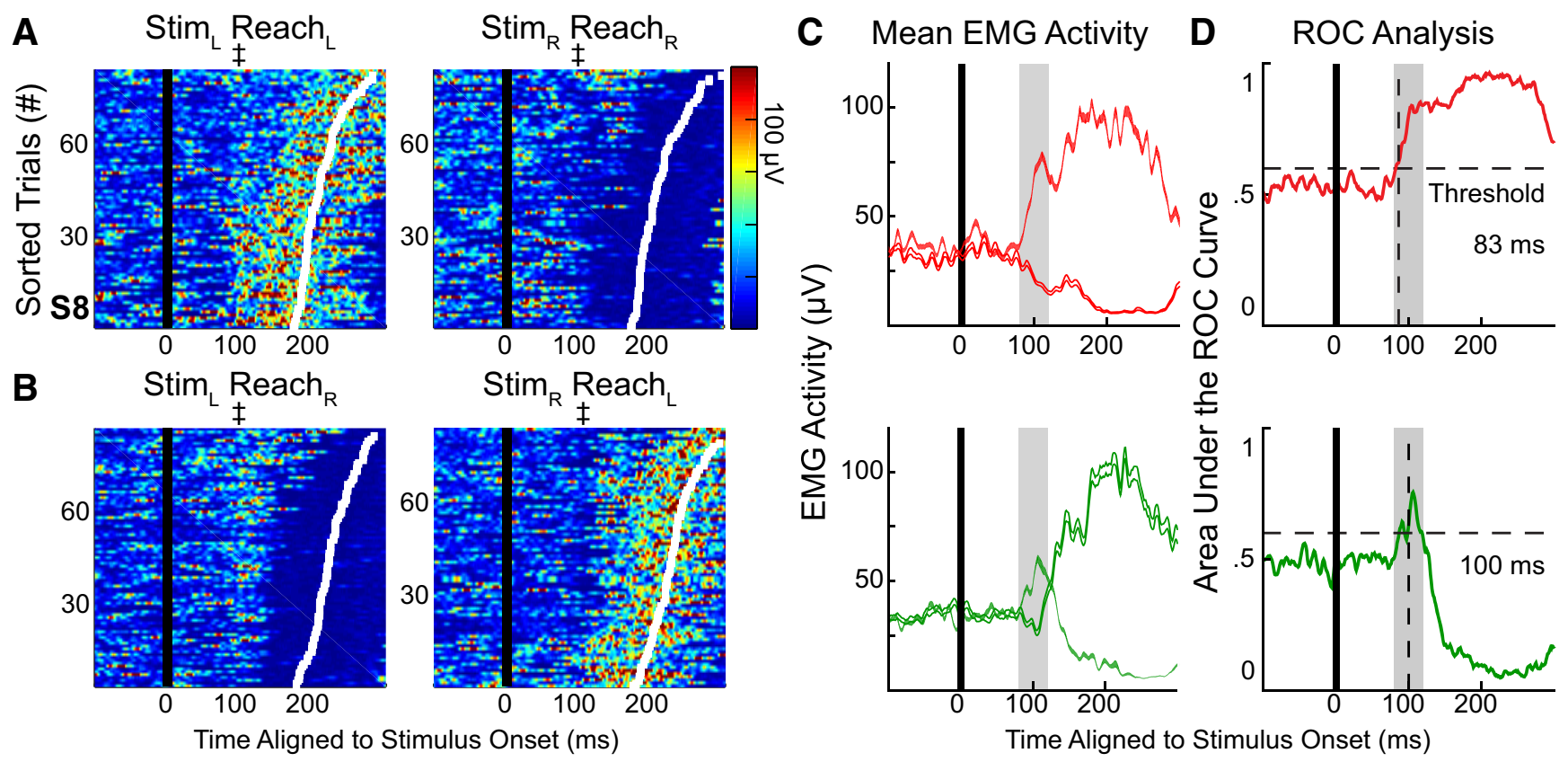

Figure 7. SLRs can be detected with surface EMG recordings. Surface EMG recordings from the exemplar subject are shown using the same format as in Figure 2.A, B, Single-trial EMG activity from pro-reach and anti-reach trials, respectively. C, Average EMG activity (mean \pm SEM) for the four different trial types. D, Time-series ROC analysis.

characteristics observed with intramuscular recordings. Across all 6 of these subjects, SLRs were significantly attenuated before correct anti-reaches compared with pro-reaches (paired $t$ test, $t_{(5)}=3.11, p<0.05$ ). The correlation between SLR magnitude and ensuing RT were reversed for pro-reaches versus anti-reaches for both leftward and rightward stimuli
( $p=0.037$ and $p=0.0142$, respectively). For the two subjects with sufficient erroneous anti-reach trials, the SLRs preceding anti-reach errors resembled those of pro-reach trials (independent $t$ test, all $p>0.1$ ), but were significantly stronger than those preceding correct anti-reach trials (independent $t$ test, all $p<0.05)$. Our successful detection of the SLR may be 
related to a combination of the posture adopted by the subject, the robotic manipulandum used, or the application of a constant load to increase background EMG activity on the muscle of interest. Regardless, demonstrating the efficacy of surface recordings will help to broaden the study of the SLR, particularly in clinical populations.

\section{Discussion}

Our results demonstrate that a fast visuomotor response, the SLR, can provide a window into the integration of visual input with cognitive control in humans. Here, by having subjects reach either toward (pro-reach) or away (anti-reach) from a peripheral visual stimulus, we showed that the initial recruitment of an upper limb muscle encodes the location of the visual stimulus, with subsequent muscle recruitment evolving to drive the taskappropriate command. SLR magnitude attenuated when subjects correctly reached away from the stimulus. Furthermore, SLR magnitude correlated with ensuing reach RT, but such correlations were reversed when subjects moved either toward or away from the visual stimulus. Overall, our results bear remarkable resemblance to neurophysiological recordings of visual responses from the frontal eye fields (FEFs) and the intermediate layers of the superior colliculus (SC) in nonhuman primates performing pro-saccades/anti-saccades (Everling et al., 1999; Everling and Munoz, 2000). Accordingly, the SLR may provide a new way of assessing how sensory input is integrated with cognitive control on a trial-by-trial basis in humans.

\section{Influence of task instruction on visual processing}

Previous work has shown that visual representations can be modulated by task instruction as early as the lateral geniculate nucleus (McAlonan et al., 2008), with such modulation being ubiquitous throughout visual and oculomotor areas in striate, extrastriate, parietal, frontal cortices, and the SC (Wurtz and Goldberg, 1972; Goldberg and Bushnell, 1981; Moran and Desimone, 1985; Colby et al., 1996). Our results show that the human SLR is also modulated by task instruction, with trial-by-trial fluctuation in SLR magnitude correlating with aspects of the ensuing behavioral response. Many neurophysiological results have reported similar trial-by-trial correlation between the magnitude of the visual response with ensuing RT (Lee et al., 2010; Marino et al., 2012; Galashan et al., 2013; Sharma et al., 2015). Furthermore, the strength of single-trial correlations between SLR magnitude and ensuing RT are comparable to that observed previously for correlations between activity of neurons in the FEFs and SC with saccadic RT (Dorris et al., 1997; Everling and Munoz, 2000). Indeed, the relationship between the SLR and ensuing RT is particularly noteworthy because it marks the first time to our knowledge that a direct, within-trial measurement of visual encoding has been reported in healthy humans using noninvasive measurements.

As mentioned above, the SLR recorded from the human limb exhibits many of the same characteristics as seen for visual responses in the oculomotor system during interleaved prosaccade and anti-saccade trials. Although there have been neurophysiological investigations of pro-reach and anti-reaches, such studies were not designed to assess the effects of task instruction on the processing of the initial visual stimulus. Some studies have used a variation of a stimulus-response compatibility task, in which a different peripheral visual stimulus instructed the subjects to make pro-reaches versus anti-reaches (Georgopoulos et al., 1989; Crammond and Kalaska, 1994; Zhang et al., 1997). Other studies have provided the task instruction and stimulus simultaneously, but required subjects to withhold movement onset for a proscribed delay period (Gail and Andersen, 2006; Gail et al., 2009; Klaes et al., 2011). Our results strongly imply that many of the lessons learned from the oculomotor system about contextual processing of visual information extend to the reaching system, providing one uses a similar task structure.

\section{SLR has a visual, not goal-directed, nature}

The fact that the SLR encodes the visual stimulus and not the motor goal is inconsistent with the involvement of the corticospinal system for the SLR. First, although transient visual responses have been reported in reach-related areas such as primary motor (Kwan et al., 1981), premotor (Weinrich and Wise, 1982), and parietal cortices (Snyder et al., 1998; Cui and Andersen, 2011), the latencies of such responses in nonhuman primates exceed $100 \mathrm{~ms}$ and therefore are too late to be driving the SLR in humans. Furthermore, the central observation that the SLR encodes the location of the visual stimulus is inconsistent with involvement of the motor cortices: although preparatoryperiod or delay-period activity in primary, premotor, and parietal cortices can encode multiple potential reaching targets (Cisek and Kalaska, 2005; Cui and Andersen, 2011), even in the context of an anti-reaching task (Klaes et al., 2011), such activity remains divorced from muscle recruitment in the periphery up until the subject makes a commitment to move (Tanji and Evarts, 1976; Kaufman et al., 2014). Based on these considerations, it seems unlikely that the SLR arises from signals relayed along a direct corticospinal pathway.

\section{SLR is potentially mediated though a reticulospinal pathway} An alternative descending motor pathway for the SLR is the reticulospinal pathway (Lemon, 2008), which is very important for postural control and orienting of the trunk (Lawrence and Kuypers, 1968). The reticulospinal pathway is thought to have a comparatively weaker effect on motoneurons than the corticospinal pathway (Riddle et al., 2009), which is consistent with the relatively small magnitude of the SLR. The reticulospinal pathway has also been implicated in online corrective reach movements, which can be initiated within $150 \mathrm{~ms}$ after stimulus displacement (Carlton, 1981; Saunders and Knill, 2004; Saijo et al., 2005; Franklin and Wolpert, 2008), can occur without perception of stimulus displacement (Goodale et al., 1986), and persist even in a subject with a complete agenesis of their corpus callosum (Day and Brown, 2001). Our results resemble those reported by Day and Lyon (2000), who studied online corrective movements in healthy subjects who had to point either toward (pro-trials) or away from (anti-trials) a displaced stimulus. They reported two distinct phases in subjects' hand trajectory: an early $(<160 \mathrm{~ms})$ small component that invariably moved toward the displaced visual stimulus on both pro-trials and anti-trials, which they attributed to the reticulospinal pathway, and a later $(>160$ ms) component that corresponded to the task goal. When considered alongside these findings, our results strongly imply that the SLR is relayed to the motor periphery via the reticulospinal system.

\section{Potential sources for task-dependent modulation of the SLR}

Assuming that the SLR is relayed through a reticulospinal pathway and given that its short latency precludes processing in motor cortices, presumably, some node between the retina and reticular formation must be modulated by task-related signals before the arrival of visual information. Within the brainstem, the SC is an obvious candidate and we have emphasized the similarity be- 
tween our results and SC activity on anti-saccade trials (Everling et al., 1998, 1999). The SC receives extensive projections from frontal and parietal cortices that convey task-related signals and the SC is itself strongly interconnected with premotor centers for orienting eye, head, and limb and torso movements (for review, see Corneil and Munoz, 2014). Visual neurons in the SC respond within 50 ms of stimulus onset (Wurtz and Goldberg, 1972) and a subset of these neurons are active only before reaches, not saccades (Song and McPeek, 2015). The SC is also thought to mediate SLRs on neck muscles in primates (Rezvani and Corneil, 2008; Chapman and Corneil, 2011), which bears many similarities to the limb SLR shown here. In addition, neurons in intermediate and deep SC are active before reaching movements (Werner, 1993), with the activity of such neurons correlating well with EMG activity on upper limb muscles (Werner et al., 1997; Stuphorn et al., 1999). Electrical stimulation within the SC can also evoke limb movements in both cats and primates (Cowie et al., 1994; Courjon et al., 2004; Philipp and Hoffmann, 2014). Finally, human fMRI experiments have reported reach-related BOLD activity in the deep layers of SC that is distinct from saccade-related activity (Linzenbold and Himmelbach, 2012; Himmelbach et al., 2013). The SC appears to be a logical node where cognitive control could influence the vigor of short-latency visual signals that are destined for the reticular formation.

\section{SLR as an alternative biomarker for the fast visuomotor response}

Although neurophysiological studies are required to prove that the tectoreticulospinal system provides the substrate for the SLR, and perhaps online corrections more generally, there are a number of important implications for our findings. First, the SLR can be detected even though the subject started from a static posture and evolves well in advance of voluntary movement (Fig. 3). Attributing different components of muscle recruitment to different descending pathways during online corrective movements is far more complicated, both because of the ongoing muscle recruitment accompanying the initial movement and because the voluntary component of the corrective movement is itself expedited due to an already-made commitment to move (Cluff and Scott, 2015). Studying the SLR from a static posture may, somewhat paradoxically, simplify the study of the fast visuomotor response. Perhaps more fundamentally, it is clear that SLR magnitude is modulated by top-down control, with such modulation being quantifiable at a trial-by-trial resolution that is unprecedented for human studies. Therefore, our ability to detect the SLR with surface recordings is particularly encouraging because the SLR may provide a novel and accessible biomarker with which to better understand how visual input integrates with cognitive control in both clinical (Chan et al., 2005; Antoniades et al., 2013) and developmental (Luna et al., 2015) studies in humans.

\section{References}

Antoniades C, Ettinger U, Gaymard B, Gilchrist I, Kristjánsson A, Kennard C, John Leigh R, Noorani I, Pouget P, Smyrnis N, Tarnowski A, Zee DS, Carpenter RH (2013) An internationally standardised antisaccade protocol. Vis Res 84:1-5. CrossRef Medline

Carlton LG (1981) Processing visual feedback information for movement control. J Exp Psychol Hum Percept Perform 7:1019-1030. CrossRef Medline

Carpenter RH, Williams ML (1995) Neural computation of log likelihood in control of saccadic eye movements. Nature 377:59-62. CrossRef Medline

Chan F, Armstrong IT, Pari G, Riopelle RJ, Munoz DP (2005) Deficits in saccadic eye-movement control in Parkinson's disease. Neuropsychologia 43:784-796. CrossRef Medline
Chapman BB, Corneil BD (2011) Neuromuscular recruitment related to stimulus presentation and task instruction during the anti-saccade task. Eur J Neurosci 33:349-360. CrossRef Medline

Churchland MM, Yu BM, Cunningham JP, Sugrue LP, Cohen MR, Corrado GS, Newsome WT, Clark AM, Hosseini P, Scott BB, Bradley DC, Smith MA, Kohn A, Movshon JA, Armstrong KM, Moore T, Chang SW, Snyder LH, Lisberger SG, Priebe NJ, et al. (2010) Stimulus onset quenches neural variability: a widespread cortical phenomenon. Nat Neurosci 13: 369-378. CrossRef Medline

Cisek P, Kalaska JF (2005) Neural correlates of reaching decisions in dorsal premotor cortex: specification of multiple direction choices and final selection of action. Neuron 45:801-814. CrossRef Medline

Cluff T, Scott SH (2016) Online corrections are faster because movement initiation must disengage postural control. Motor Control 20:162-170. CrossRef Medline

Colby CL, Duhamel JR, Goldberg ME (1996) Visual, presaccadic, and cognitive activation of single neurons in monkey lateral intraparietal area. J Neurophysiol 76:2841-2852. Medline

Corneil BD, Munoz DP (2014) Overt responses during covert orienting. Neuron 82:1230-1243. CrossRef Medline

Corneil BD, Olivier E, Munoz DP (2004) Visual responses on neck muscles reveal selective gating that prevents express saccades. Neuron 42: 831-841. CrossRef Medline

Courjon JH, Olivier E, Pélisson D (2004) Direct evidence for the contribution of the superior colliculus in the control of visually guided reaching movements in the cat. J Physiol 556:675-681. CrossRef Medline

Cowie RJ, Smith MK, Robinson DL (1994) Subcortical contributions to head movements in macaques. II. Connections of a medial pontomedullary head-movement region. J Neurophysiol 72:2665-2682. Medline

Crammond DJ, Kalaska JF (1994) Modulation of preparatory neuronal activity in dorsal premotor cortex due to stimulus-response compatibility. J Neurophysiol 71:1281-1284. Medline

Cui H, Andersen RA (2011) Different representations of potential and selected motor plans by distinct parietal areas. J Neurosci 31:18130-18136. CrossRef Medline

Day BL, Brown P (2001) Evidence for subcortical involvement in the visual control of human reaching. Brain 124:1832-1840. CrossRef Medline

Day BL, Lyon IN (2000) Voluntary modification of automatic arm movements evoked by motion of a visual target. Exp Brain Res 130:159-168. CrossRef Medline

Dorris MC, Paré M, Munoz DP (1997) Neuronal activity in monkey superior colliculus related to the initiation of saccadic eye movements. J Neurosci 17:8566-8579. Medline

Everling S, Munoz DP (2000) Neuronal correlates for preparatory set associated with pro-saccades and anti-saccades in the primate frontal eye field. J Neurosci 20:387-400. Medline

Everling S, Dorris MC, Munoz DP (1998) Reflex suppression in the antisaccade task is dependent on prestimulus neural processes. J Neurophysiol 80:1584-1589. Medline

Everling S, Dorris MC, Klein RM, Munoz DP (1999) Role of primate superior colliculus in preparation and execution of anti-saccades and prosaccades. J Neurosci 19:2740-2754. Medline

Franklin DW, Wolpert DM (2008) Specificity of reflex adaptation for taskrelevant variability. J Neurosci 28:14165-14175. CrossRef Medline

Gail A, Andersen RA (2006) Neural dynamics in monkey parietal reach region reflect context-specific sensorimotor transformations. J Neurosci 26:9376-9384. CrossRef Medline

Gail A, Klaes C, Westendorff S (2009) Implementation of spatial transformation rules for goal-directed reaching via gain modulation in monkey parietal and premotor cortex. J Neurosci 29:9490-9499. CrossRef Medline

Galashan FO, Saßen HC, Kreiter AK, Wegener D (2013) Monkey area MT latencies to speed changes depend on attention and correlate with behavioral reaction times. Neuron 78:740-750. CrossRef Medline

Gallivan JP, Logan L, Wolpert DM, Flanagan JR (2016) Parallel specification of competing sensorimotor control policies for alternative action options. Nat Neurosci 19:320-326. CrossRef Medline

Georgopoulos AP, Lurito JT, Petrides M, Schwartz AB, Massey JT (1989) Mental rotation of the neuronal population vector. Science 243:234-236. CrossRef Medline

Goldberg ME, Bushnell MC (1981) Behavioral enhancement of visual re- 
sponses in monkey cerebral cortex. II. Modulation in frontal eye fields specifically related to saccades. J Neurophysiol 46:773-787. Medline

Goodale MA, Pelisson D, Prablanc C (1986) Large adjustments in visually guided reaching do not depend on vision of the hand or perception of target displacement. Nature 320:748-750. CrossRef Medline

Goonetilleke SC, Katz L, Wood DK, Gu C, Huk AC, Corneil BD (2015) Cross-species comparison of anticipatory and stimulus-driven neck muscle activity well before saccadic gaze shifts in humans and non-human primates. J Neurophysiol 114:902-913. CrossRef Medline

Gottlieb J, Goldberg ME (1999) Activity of neurons in the lateral intraparietal area of the monkey during an antisaccade task. Nat Neurosci 2: 906-912. CrossRef Medline

Hallett PE (1978) Primary and secondary saccades to goals defined by instructions. Vis Res 18:1279-1296. CrossRef Medline

Himmelbach M, Linzenbold W, Ilg UJ (2013) Dissociation of reach-related and visual signals in the human superior colliculus. Neuroimage 82:6167. CrossRef Medline

Kaufman MT, Churchland MM, Ryu SI, Shenoy KV (2014) Cortical activity in the null space: permitting preparation without movement. Nat Neurosci 17:440-448. CrossRef Medline

Klaes C, Westendorff S, Chakrabarti S, Gail A (2011) Choosing goals, not rules: deciding among rule-based action plans. Neuron 70:536-548. CrossRef Medline

Kristjánsson A, Chen Y, Nakayama K (2001) Less attention is more in the preparation of antisaccades, but not prosaccades. Nat Neurosci 4:10371042. CrossRef Medline

Kwan HC, MacKay WA, Murphy JT, Wong YC (1981) Distribution of responses to visual cues for movement in precentral cortex or awake primates. Neurosci Lett 24:123-128. CrossRef Medline

Lawrence DG, Kuypers HG (1968) The functional organization of the motor system in the monkey. II. The effects of lesions of the descending brain-stem pathways. Brain 91:15-36. CrossRef Medline

Lee J, Kim HR, Lee C (2010) Trial-to-trial variability of spike response of V1 and saccadic response time. J Neurophysiol 104:2556-2572. CrossRef Medline

Lemon RN (2008) Descending pathways in motor control. Annu Rev Neurosci 31:195-218. CrossRef Medline

Linzenbold W, Himmelbach M (2012) Signals from the deep: reach-related activity in the human superior colliculus. J Neurosci 32:13881-13888. CrossRef Medline

Luce RD (1986) Response times: their role in inferring elementary mental organization. New York: OUP.

Luna B, Marek S, Larsen B, Tervo-Clemmens B, Chahal R (2015) An integrative model of the maturation of cognitive control. Annu Rev Neurosci 38:151-170. CrossRef Medline

Marino RA, Levy R, Boehnke S, White BJ, Itti L, Munoz DP (2012) Linking visual response properties in the superior colliculus to saccade behavior. Eur J Neurosci 35:1738-1752. CrossRef Medline

McAlonan K, Cavanaugh J, Wurtz RH (2008) Guarding the gateway to cortex with attention in visual thalamus. Nature 456:391-394. CrossRef Medline

Moran J, Desimone R (1985) Selective attention gates visual processing in the extrastriate cortex. Science 229:782-784. CrossRef Medline

Munoz DP, Everling S (2004) Look away: the anti-saccade task and the voluntary control of eye movement. Nat Rev Neurosci 5:218-228. CrossRef Medline

Norman RW, Komi PV (1979) Electromechanical delay in skeletal muscle under normal movement conditions. Acta Physiol Scand 106:241-248. CrossRef Medline
Philipp R, Hoffmann KP (2014) Arm movements induced by electrical microstimulation in the superior colliculus of the macaque monkey. J Neurosci 34:3350-3363. CrossRef Medline

Posner MI (1986) Chronometric explorations of mind. New York: OUP.

Pruszynski JA, King GL, Boisse L, Scott SH, Flanagan JR, Munoz DP (2010) Stimulus-locked responses on human arm muscles reveal a rapid neural pathway linking visual input to arm motor output. Eur J Neurosci 32: 1049-1057. CrossRef Medline

Rezvani S, Corneil BD (2008) Recruitment of a head-turning synergy by low-frequency activity in the primate superior colliculus. J Neurophysiol 100:397-411. CrossRef Medline

Riddle CN, Edgley SA, Baker SN (2009) Direct and indirect connections with upper limb motoneurons from the primate reticulospinal tract. J Neurosci 29:4993-4999. CrossRef Medline

Saijo N, Murakami I, Nishida S, Gomi H (2005) Large-field visual motion directly induces an involuntary rapid manual following response. J Neurosci 25:4941-4951. CrossRef Medline

Saunders JA, Knill DC (2004) Visual feedback control of hand movements. J Neurosci 24:3223-3234. CrossRef Medline

Schall JD (2003) Neural correlates of decision processes: neural and mental chronometry. Curr Opin Neurobiol 13:182-186. CrossRef Medline

Schmolesky MT, Wang Y, Hanes DP, Thompson KG, Leutgeb S, Schall JD, Leventhal AG (1998) Signal timing across the macaque visual system. J Neurophysiol 79:3272-3278. Medline

Sharma J, Sugihara H, Katz Y, Schummers J, Tenenbaum J, Sur M (2015) Spatial attention and temporal expectation under timed uncertainty predictably modulate neuronal responses in monkey V1. Cereb Cortex 25: 2894-2906. CrossRef Medline

Snyder LH, Batista AP, Andersen RA (1998) Change in motor plan, without a change in the spatial locus of attention, modulates activity in posterior parietal cortex. J Neurophysiol 79:2814-2819. Medline

Song JH, McPeek RM (2015) Neural correlates of target selection for reaching movements in superior colliculus. J Neurophysiol 113:1414-1422. CrossRef Medline

Stuphorn V, Hoffmann KP, Miller LE (1999) Correlation of primate superior colliculus and reticular formation discharge with proximal limb muscle activity. J Neurophysiol 81:1978-1982. Medline

Tanji J, Evarts EV (1976) Anticipatory activity of motor cortex neurons in relation to direction of an intended movement. J Neurophysiol 39:10621068. Medline

Weinrich M, Wise SP (1982) The premotor cortex of the monkey. J Neurosci 2:1329-1345. Medline

Werner W (1993) Neurons in the primate superior colliculus are active before and during arm movements to visual targets. Eur J Neurosci 5: 335-340. CrossRef Medline

Werner W, Dannenberg S, Hoffmann KP (1997) Arm-movement-related neurons in the primate superior colliculus and underlying reticular formation: comparison of neuronal activity with EMGs of muscles of the shoulder, arm and trunk during reaching. Exp Brain Res 115:191-205. CrossRef Medline

Wood DK, Gu C, Corneil BD, Gribble PL, Goodale MA (2015) Transient visual responses reset the phase of low-frequency oscillations in the skeletomotor periphery. Eur J Neurosci 42:1919-1932. CrossRef Medline

Wurtz RH, Goldberg ME (1972) Activity of superior colliculus in behaving monkey. 3. Cells discharging before eye movements. J Neurophysiol 35: 575-586. Medline

Zhang J, Riehle A, Requin J, Kornblum S (1997) Dynamics of single neuron activity in monkey primary motor cortex related to sensorimotor transformation. J Neurosci 17:2227-2246. Medline 